\title{
STEEL STRUCTURES IN INTERACTION WITH NON-METALLIC MEMBRANES
}

\author{
Josef MACHACEK ${ }^{\mathrm{a}}$, David JERMOLJEV ${ }^{\mathrm{b}}$ \\ ${ }^{a}$ Faculty of Civil Engineering, Czech Technical University in Prague, \\ Thakurova 7, 16629 Prague, Czech Republic \\ ${ }^{b}$ EXCON corp., Sokolovska 187/203, 19000 Prague, Czech Republic
}

Received 18 Jun 2015; accepted 24 Sep 2015

\begin{abstract}
Behaviour of prestressed textile membranes supported by peripheral non-rigid steel structures and used for various simple temporary and permanent canopies/shelters is described. The investigation relates to structures composed of membranes located between steel arches only. The approaches for global analysis of the structural system and influence of important parameters such as the membrane prestressing and rigidity of the supporting steelwork are discussed. Extensive parametric study concerning possibility of simplified separate analyses of the membranes and supporting steel structures is presented, giving limiting parameters for such approach. Finally, some recommendations for the analysis and realization of prestressed non-metallic membranes and respective steel supporting structures are provided.
\end{abstract}

Keywords: formfinding, pre-stressing, nonlinear analysis, separate analysis, steel arch, textile membranes.

\section{Introduction}

In the last decades the use of non-metallic membranes is widespread due to their enormous lightness and aesthetics required by architects, developers and investors. The world-famous companies (e.g. Base Structures Ltd., FabriTec Structures, TI Tensile structures, Oasis Tension Structures, Mehler Ltd., Archtex s.r.o., Herzog \& de Meuron, Vector Foiltec, etc.) are producing countless number of both ordinary and unique tensile structures using fabric or foil membranes.

Textile membranes are becoming required and routine material not only for simple canopies or shelters but also for sophisticated outward load bearing structures. Nowadays a detailed survey of available textile/foil materials suitable for membrane engineering structures is displayed in specialized websites and publications. For example Base Structures Ltd. presents a table mapping the most common external and internal fabrics with basic data on their lifetime, price, joining, fire rating, translucence, possibility of relocation, colour etc.

For common modest use the PVC coated polyester (PES/PVC) seems to be appropriate as an inexpensive variant, giving up to 20 years of lifetime (e.g. Précontraint FERRARI ${ }^{\circledR}$ ), joined by welding or sewing. More expensive but longer lifetime provides glass fabric coated by PTFE (Glass/PTFE), with possible replacement of PTFE (Teflon) by silicon rubber or titanium dioxide, and joined by bonding. Rather expensive but excellent material is expanded PTFE coated 2 sides by fluoropolymer film (TENARA ${ }^{\circledR}$ ), joined by welding. The membranes may also be thermally insulated using Nanogel Aerogel ${ }^{\mathrm{TM}}$ and 2 sides coated with PTFE (in result translucent, with total thickness of approx. $9 \mathrm{~mm}$, see CABOT Cor.). High density polyethylene fabrics (HDPE, coated with LDPE) joined by sewing may also be used, however, with short lifespan up to 10 years. Thin foils $(50 \div 500 \mu \mathrm{m})$ are used mainly as inflatable cushions, nowadays predominantly made from ETFE (TEXLON ${ }^{\circledR}$ ) or THV materials.

Spectacular structures using textile/foil membranes (e.g. Millennium Dome in London, amphitheatre Memorial dos Povos de Belém do Pará, Metrodome roof in Minnesota, Rosenheim Bahnhof, Allianz Arena Munich, Khan Shatyr Astana, Hajj Terminal Jeddah, Duol domes, etc.) indicate new ways, forms and directions of novel unique structures.

Design of a membrane structure follows general concept (Lewis 2003): i) the predesign of a form ensuring tension within the all membrane area during assembly and loading, requiring a sufficient prestressing: basic shapes are hypar, cone and barrel (Seidel 2009); ii) the decision on boundary conditions (point or continuous and rigid or elastic boundaries) and used peripheral elements (prestressed cables, frame structure, anchor points and cables); iii) form-finding process based usually on the

Corresponding author: Josef Machacek

E-mail: machacek@fsv.cvut.cz 
force-density method (Formfinder software GmbH 20062015); iv) structural analysis of the membrane with supporting structure under required prestressing, dead and live loading - i.e. snow, wind, facility (Foster, Mollaert 2004; Wakefield 1999). The prestressing procedure often determines the design and final geometry of the resulting structure.

Formfinding process based on force-density method with cable network model (Schek 1974; Linkwitz 1999; Gründig et al. 2000) enabled to abandon former physical modelling of membrane structures and former simple grid method (Siev, Eidelman 1964). More general approach offered surface stress density method (Maurin, Motro 1998) with isotropic membrane elements and stress distribution control. Recent formfinding efficient methods embody updated reference strategy method (Bonet, Mahaney 2001) and modified updated reference strategy method (Cottrell et al. 2009; Capova 2010) which solve the variation task with isogeometric analysis based on non-uniform B-spline base representations (NURBS), using FEM and N-R iteration. In the last decade an intensive effort by Roithmayr and Gründig (Formfinder software $\mathrm{GmbH}$ 2006-2015) resulted in software as a user-friendly tool with large project database. The software enables intuitive manipulation with membrane shapes under required stress level in interactive way and export/import to other programmes through DXF/DWG files. Constantly improved versions upgrade the software even for design of supporting elements.

Geometrically and materially non-linear analysis considering imperfections (GMNIA) is required for proper dealing with membranes acting together with a supporting steelwork. Material properties of common textile membranes are under continuous investigations. The material is due to its structure non-homogeneous, orthotropic (warp and fill directions) and non-linear. Such sophisticated formulation based on fabric lattice was proposed (Kato et al. 1999), which well corresponded with test data but is considered as too complicated for practical analysis. Gosling (2007), apart from a simplified approach, suggested strain-strain-stress approach using response surfaces linking strains to stresses through three dimensional representations for FE analysis. Recently a non-linear material model for textile membranes based on experimental results was proposed (Galliot, Luchsinger 2009a, 2009b). The model depends on load ratios in warp and fill directions and is described by five parameters: warp and fill Young's modules for 1:1 load ratio, the change in warp and fill Young's modules and the Poisson's ratio. Another new model (Dinh et al. 2014) is based on input from uniaxial and biaxial tension test data, which properly simulate relevant nonlinearities, orthotropic behaviour and permanent strains with load cycling. The latest material model (Pargana, Leitao 2015) consists of three nonlinear elements to model yarns and an isotropic plate to model coating. The model is claimed to be simple and credible as confirmed by validations with experimental results.
In accordance with the European recommendations by Tensinet Analysis \& Materials working Group (see Foster, Mollaert 2004; Gosling 2007) a simplified elastic approach may be employed using the simple plane stress theory. The supplied test data provides elastic modules for warp and fill directions and corresponding Poisson's ratio, valid for anticlastic type of structures. Recently a comparison of two approaches concerning simplified elastic constants for design of the membranes (Japanese MSAJ and the above European ones) was presented in Uhlemann et al. (2015). The European approach was found to be more general and reasonable for PES/PVC material (but still far from satisfactory).

Supporting steelwork as anchor, perimeter, valley and ridge ropes or rather stiff load-bearing structure form an integral part of the resulting membrane structure. Interaction of the membranes with the steel elements requires sophisticated analysis using specialized engineering software (see e.g. Easy Software 2014; ixForten 2015; SOFiSTiK 2014; Rhino Membrane 2015; membrane NDN software 2015, etc.) or other general FEM software packages (Wakefield 1999). With need to model properly the membrane behaviour in large tensile structures using FEM, apart from sophisticated material models the new nonlinear finite elements were developed recently. Novel quadratic membrane element was proposed (Pargana, Leitao 2015) on assumption of flat fabric patterns in their unstressed state and quadratic sliding cable element inside a fabric sleeve. The elements were incorporated into ADAPTIC software and verified in case studies. Assembly method and the prestressing ensuring the full functionality must carefully be taken into account (Seidel 2009).

Nevertheless, simple membrane structures are often designed by non-specialized consultancy offices which do not possess the specialized software. In such situations the prestressed membrane is analyzed separately as isolated one with large deflections and isotropic material behaviour while the resulting reactions are introduced into a supporting steelwork. This paper investigates only the simplest form of the membrane structures called "barrel" (Fig. 1), to assess whether the simplified separate analysis of a membrane stretched between non-rigid steel arches

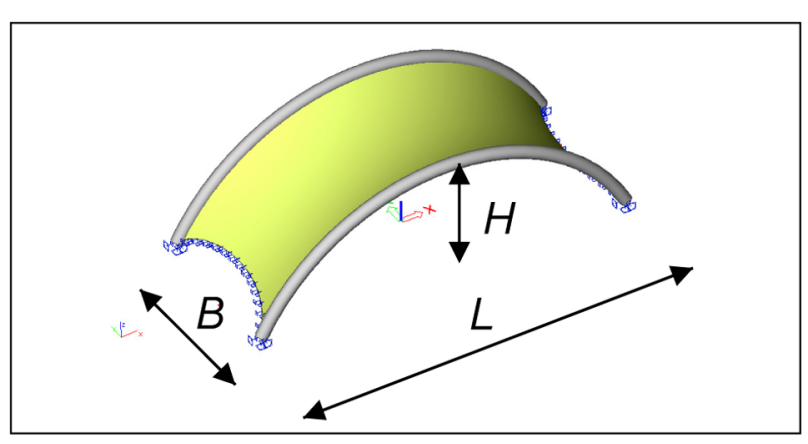

Fig. 1. Geometry of a simple membrane stretched as an anticlastic surface between two steel arches 
as a membrane alone (i.e. with rigid supports) and the steel arches (i.e. arches loaded by the relevant membrane response) is reasonable. Separate modelling may only be successful provided the design of the membrane considers geometry and rigidity of the supporting framework. In case the support is not fully rigid, the introduction of real rigidities is necessary, otherwise resultant membrane stresses and deflections are distorted and data provided to the designer of steel structure are incorrect.

Therefore, this study does not model the membranes with all the above mentioned nonlinearities and anisotropy but employs geometrically nonlinear analysis (GNA) with linear isotropic behaviour of a textile membrane, because its principal goal is investigation of the interaction with the supporting steelwork. Such simplification of membrane behaviour is well approaching the Ferrari ${ }^{\circledR}$ Précontraint type of fabric, made of polyester scrim coated both sides with liquid PVC and PVDF topcoat. Due to prestressing of the base fabric before and during the coating operations both warp and fill directions show similar behaviour, elongation and minimum creep. More sophisticated material behaviour of the fabric is used by Svoboda and Machacek (2014), concerning detailed study of the membranes.

\section{Analysis of a structure composed of a textile membrane and steel arches}

The study follows the general procedure mentioned above. First the membrane shapes were found using FORMFINDER software and transferred via AUTOCAD to the common 3D "frame" SCIA ENGINEER software. The basic shape with dimensions $L \times B \times H$ as $10000 \times 4000 \times 3000[\mathrm{~mm}]$ according to Figure 2 was found, supported by two steel tubular arches built-in at the supports and made from S235 grade steel. The textile membrane considered was fictitious isotropic material with modulus of elasticity $E=1000 \mathrm{MPa}$, Poisson's ratio $v=0.25$ and thickness $t=1 \mathrm{~mm}$. The analyses cover "membrane alone" (i.e. the membrane with rigid supports along both arches and transverse supports) and "membrane with arches" (i.e. membrane supported by non-rigid arches and rigid transverse supports, the latter always used to reduce the entry data).
The proper prestressing of the membrane to ensure tension throughout the membrane area during assembly and all loadings is required. Within the study the simple planar prestressing through confined deformation $\varepsilon=\varepsilon_{x}=\varepsilon_{y}$ was introduced into numerical analysis. In the "membrane alone" $\varepsilon=0.004$ (giving for $v=0.25$ unit force $5.333 \mathrm{~N} / \mathrm{mm}$ ), for the "membrane with arches" the value $\varepsilon=0.0046$ resulted from condition of identical horizontal reaction along arch lines to ensure the same prestressing as in the former due to horizontal deflection of arches. Vertical loading $1 \mathrm{kN} / \mathrm{m}^{2}$ only was considered in the study, representing snow loading. The arches were designed according to Eurocode 3 (EN 1993) for the above loading. The tubes $324 \times 25$ [mm] ensure cross-section utilization of approx. $80 \%$.

Geometrically nonlinear analysis (GNA) with proper boundary shape was performed, arches modelled by beam and the membrane by quadrilateral elements. First a sensitivity of the finite element size was assessed for the case of "membrane alone" through three mesh divisions, with basic lengths $50 \mathrm{~mm}, 150 \mathrm{~mm}, 250 \mathrm{~mm}$, Figure 3 .

After decreasing size from $150 \mathrm{~mm}$ to $50 \mathrm{~mm}$ the deflections remained nearly unaffected (see Fig. 4) and stresses increased by $5.1 \%$. After increasing the size from $150 \mathrm{~mm}$ to $250 \mathrm{~mm}$ the deflections decreased by $0.1 \%$ and stresses decreased by $2.6 \%$. The finest mesh gives more appropriate results for detailed stresses in corners/ edges. In all the following studies the medium mesh $(150 \mathrm{~mm})$ was used and considered adequate even for the parametric studies.

The above analysis was compared with results of another nonlinear solution using common COMSOL MULTIPHYSICS software, and found to be nearly identical.

\section{Comparison of results based on full and separate analyses}

\subsection{The full "membrane with arches" and "membrane alone" analysis}

GNA was performed for the directionless (confined) prestressing as defined above, to give the identical horizontal reaction along arch lines for both boundary conditions. The resulting transverse unit forces due to the prestressing are

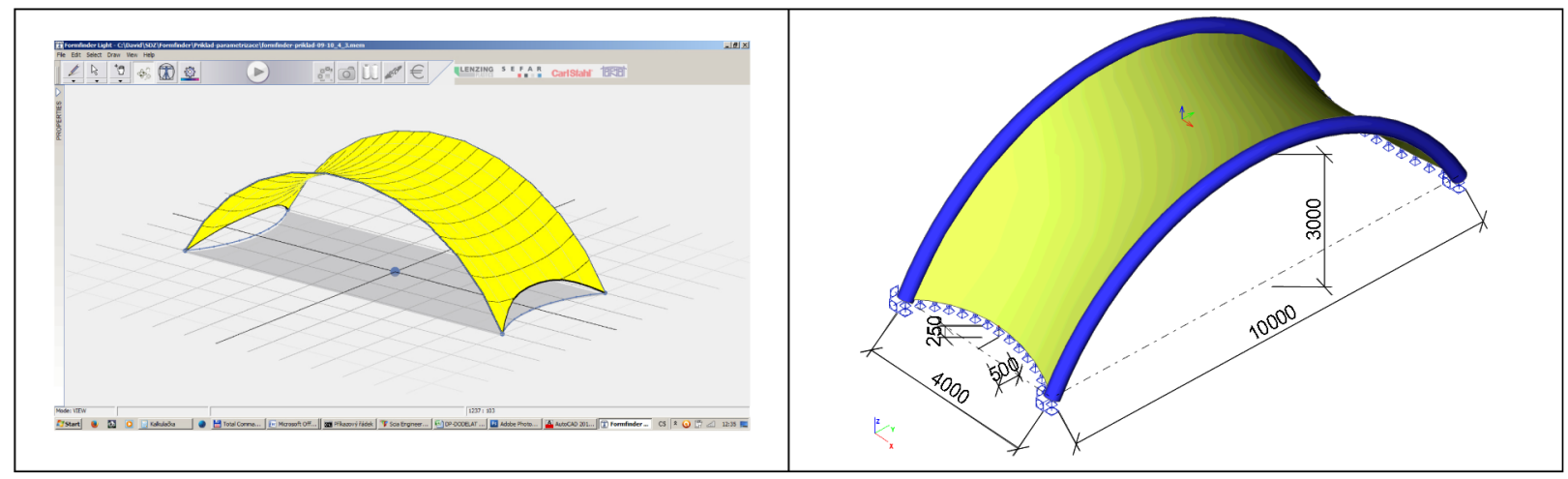

Fig. 2. Shape according to FORMFINDER software (left) and investigated geometry (right) 


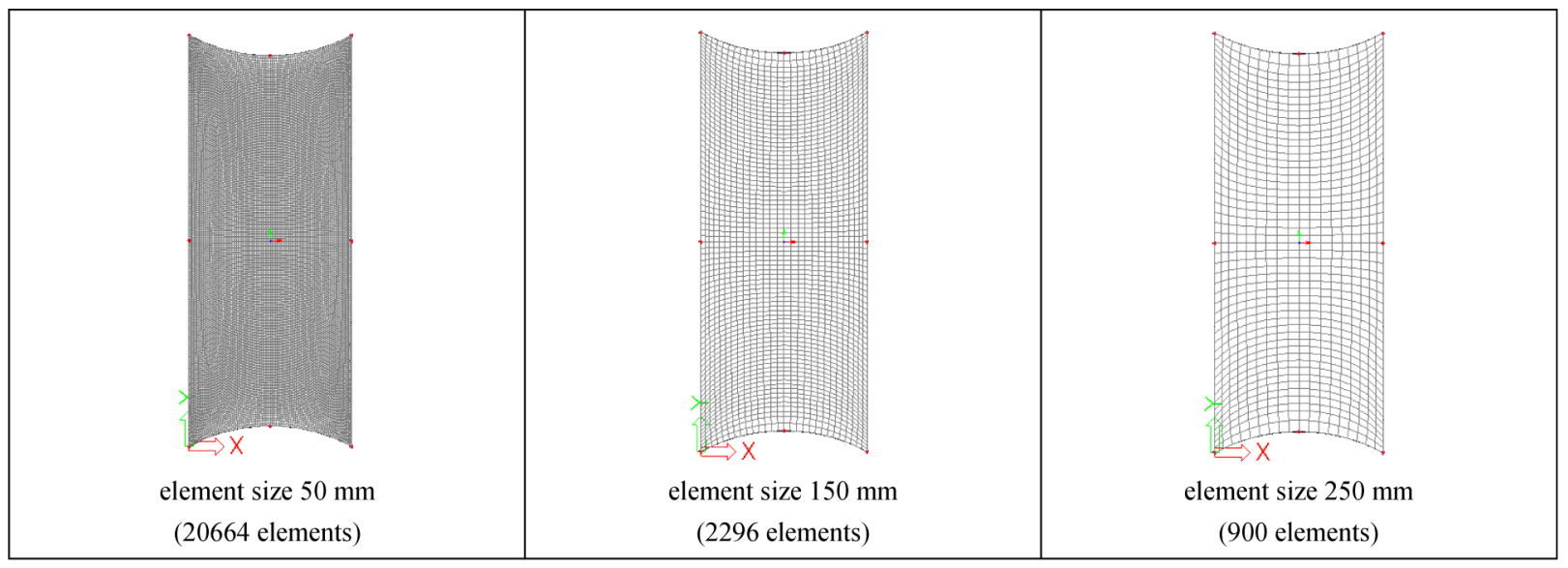

Fig. 3. Element divisions of the membrane

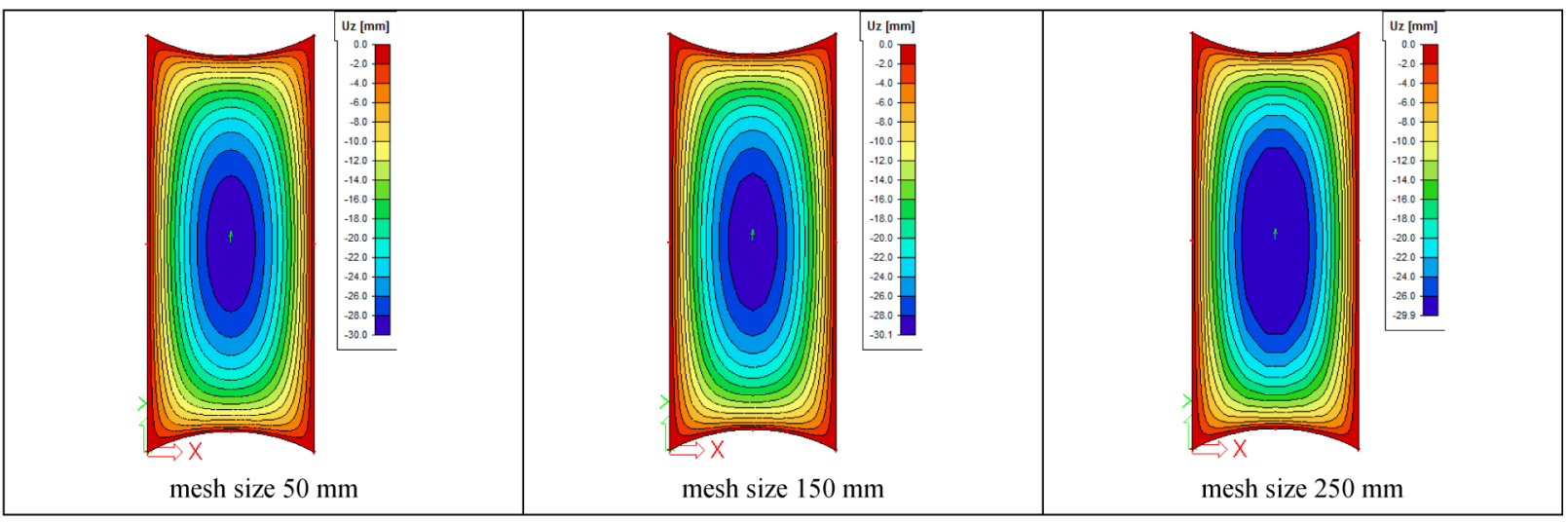

Fig. 4. Vertical deflections

shown in Figure 5. In the case of rigid boundary ("membrane alone" analysis) the maximal forces attain just $92 \%$ of the maximal forces in the first case ("membrane with arches" analysis).

More marked difference was found for the vertical loading of $1 \mathrm{kN} / \mathrm{m}^{2}$ acting together with the prestressing. The comparison of maximal transverse unit forces and membrane deflections is shown in Figure 6. In the case of the "membrane alone (i.e. membrane with fully rigid perimeter supports) the maximal transverse unit force is $11 \%$ higher but the maximal membrane deflection attains just $78 \%$ in comparison with the "membrane with arches" (i.e. membrane acting together with non-rigid steel arches).

\subsection{The "membrane alone" analyses considering elastic supports}

It is obvious, that rigidity of supporting steelwork plays important role in determining the final membrane deflection shape, final stresses and required prestressing. Therefore a simulation of the arch flexibility in the membrane direction was examined. Nevertheless, it is not easy to simulate flexible arch tubes by simplified elastic linear supports because the actual value of rigidity along the

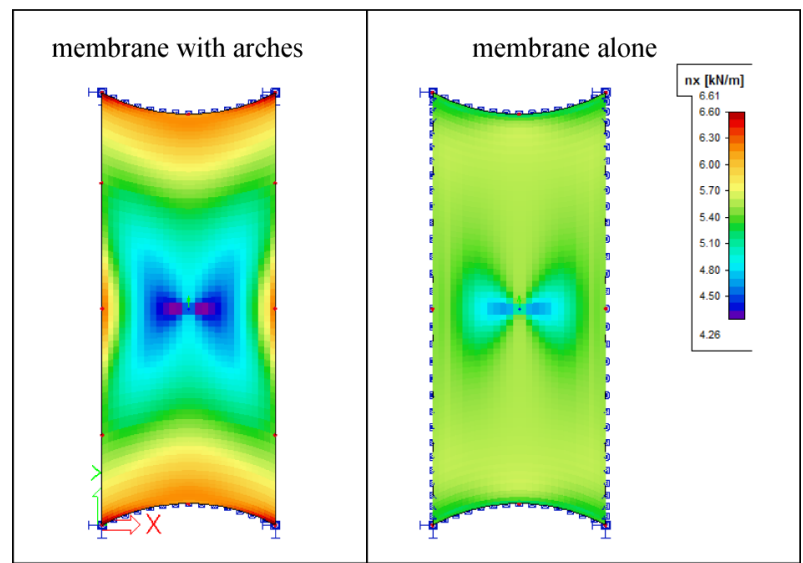

Fig. 5. Transverse membrane forces $n_{x}[\mathrm{~N} / \mathrm{mm}]$ due to prestressing

arches is changing (e.g. in the arch supports is approaching the infinity). Various elastic support rigidities with uniform distribution only along arch lines were tested. The final one, after using a trial-and-error method, resulted from condition of both the same total horizontal reaction and maximal horizontal deflection due to prestressing as in the case of the "membrane with arches". The resulting fictitious uniform elastic rigidity of 


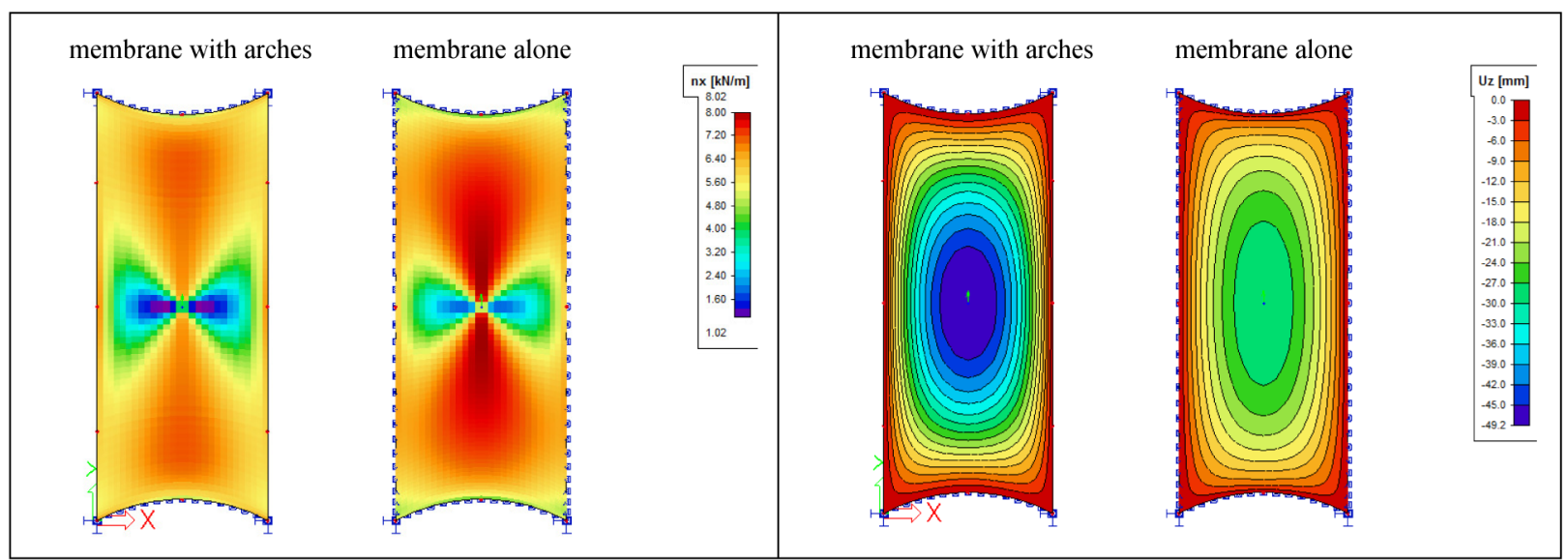

Fig. 6. Transverse membrane forces $n_{x}[\mathrm{~N} / \mathrm{mm}]$ (left) and vertical deflections $u_{z}$ [mm] (right)

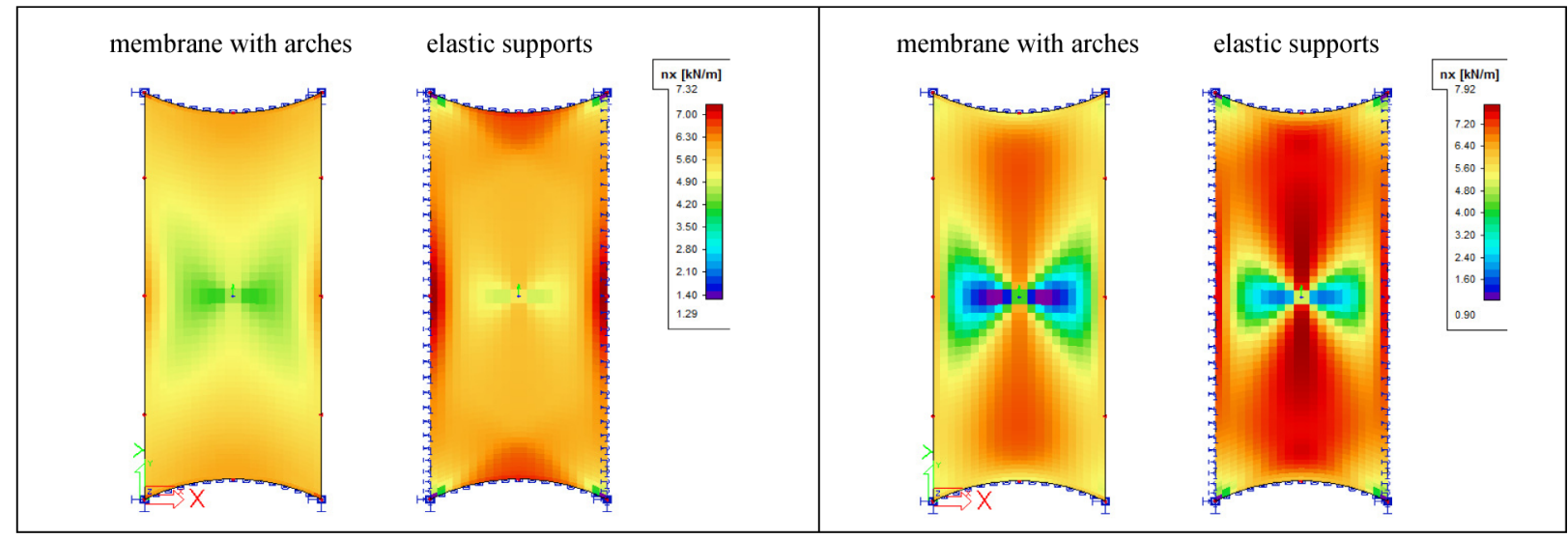

Fig. 7. Transverse membrane forces $n_{x}[\mathrm{~N} / \mathrm{mm}]$ due to prestressing (left) and due to combined prestressing and vertical loading (right)

$1950 \mathrm{~N} / \mathrm{mm}$ requires prestressing of $148 \%$ of the one corresponding to the "membrane alone". Nevertheless, the maximal transverse forces due to both prestressing and combined loading in the membrane with such elastic support are still $11 \%$ higher than in "membrane with arches" (Fig. 7).

The same holds for the von Mises equivalent stresses (Fig. 8 left). On the other side the deflections attain only $85 \%$ of the "membrane with arches" (Fig. 8 right). Clearly the separate analysis of the membrane on such elastic supports gives rather incorrect results and depends on entry arch and membrane data whether the results are acceptable.

\section{Parametrical study}

The study concerns the foregoing membrane supported by tube arches according to Figure 1. The FEM elastic nonlinear study (GNA) was performed again with a fictitious membrane (modulus of elasticity $E=1000 \mathrm{MPa}$, Poisson's ratio $v=0.25$, thickness $t=1 \mathrm{~mm}$ ). The investigation of the full "membrane with arches" and the "membrane alone" is performed for a range of practi- cal geometrical parameters given in Table 1. In total 27 structures were analyzed which were loaded in the same way as presented above in Chapter 1. It means that planar prestressing by the confined strain $\varepsilon=0.4$ was used in the "membrane alone" while for the "membrane with arches" the value of $\varepsilon$ resulted from condition of identical horizontal reaction along arch lines to ensure the same prestressing as in the former due to horizontal deflection of arches. The only other loading considered was $1 \mathrm{kN} / \mathrm{m}^{2}$ vertical loading representing snow loading and, therefore, No. 9 in the parametric study corresponds to case studied in the previous chapters. The cross-sections of the tube arches were designed according to Eurocode 3 (EN 1993) for the above loading and give cross-section utilization up to $80 \%$.

A graphical illustration of the studied cases is shown in Figure 9, accentuating the realistic ones.

The boundary conditions are demonstrated again in Figure 10, showing membrane supported along arches either on non-rigid tubes (in case of "membrane with arches") or just simply supported (in case of "membrane alone"). Transverse edges were simply supported in both cases to reduce the entry calculation parameters. 


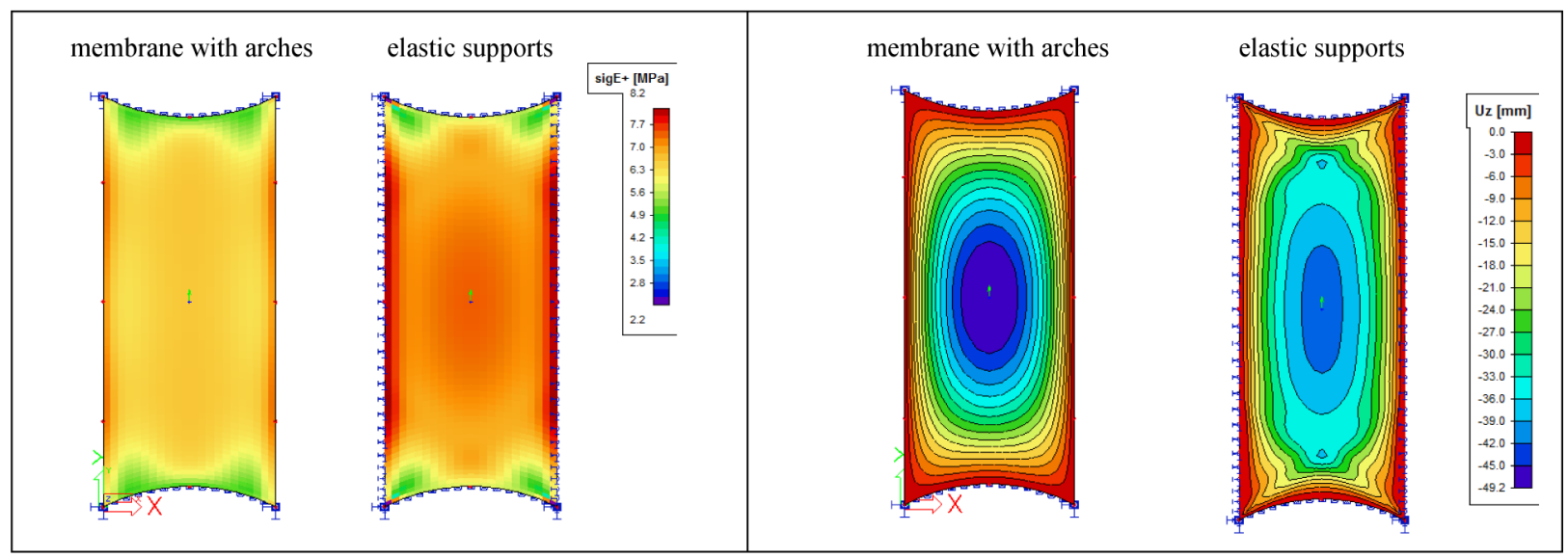

Fig. 8. Equivalent von Mises stresses due to combined prestressing and vertical loading $\sigma[\mathrm{MPa}]$ (left) and vertical deflections under combined loading $u_{z}[\mathrm{~mm}]$ (right)

Table 1. Geometrical data of the considered steelwork in accordance with Figure 1

\begin{tabular}{c|c|c|c|c|c}
\hline No. & $\begin{array}{c}\text { Span } \\
L[\mathrm{~m}]\end{array}$ & $\begin{array}{c}\text { Width } \\
B[\mathrm{~m}]\end{array}$ & $\begin{array}{c}\text { Rise } \\
H[\mathrm{~m}]\end{array}$ & $\begin{array}{c}\text { Tube } \\
D \times t[\mathrm{~mm}]\end{array}$ & $\begin{array}{c}\text { Slenderness } \\
\bar{L} / r\end{array}$ \\
\hline 1 & 4 & 2 & 1 & $273 \times 16$ & 50.95 \\
2 & 6 & 2 & 1 & $273 \times 25$ & 73.04 \\
3 & 6 & 2 & 2 & $273 \times 25$ & 86.77 \\
4 & 8 & 2 & 1 & $324 \times 20$ & 77.34 \\
5 & 8 & 2 & 2 & $324 \times 20$ & 86.10 \\
6 & 8 & 4 & 1 & $324 \times 20$ & 77.34 \\
7 & 8 & 4 & 2 & $324 \times 20$ & 86.10 \\
8 & 10 & 4 & 2 & $324 \times 25$ & 104.01 \\
9 & 10 & 4 & 3 & $324 \times 25$ & 115.46 \\
10 & 12 & 4 & 2 & $356 \times 22$ & 108.79 \\
11 & 12 & 4 & 3 & $356 \times 22$ & 117.57 \\
12 & 12 & 4 & 4 & $356 \times 22$ & 129.23 \\
13 & 12 & 6 & 2 & $356 \times 22$ & 108.79 \\
14 & 12 & 6 & 3 & $356 \times 22$ & 117.57 \\
15 & 12 & 6 & 4 & $356 \times 22$ & 129.23 \\
16 & 14 & 4 & 2 & $377 \times 20$ & 116.69 \\
17 & 14 & 4 & 3 & $377 \times 20$ & 123.86 \\
18 & 14 & 4 & 4 & $377 \times 20$ & 133.48 \\
19 & 14 & 6 & 2 & $377 \times 20$ & 116.69 \\
20 & 14 & 6 & 3 & $377 \times 20$ & 123.86 \\
21 & 14 & 6 & 4 & $377 \times 20$ & 133.48 \\
22 & 16 & 6 & 2 & $377 \times 25$ & 133.49 \\
23 & 16 & 6 & 3 & $377 \times 25$ & 139.90 \\
24 & 16 & 6 & 4 & $377 \times 25$ & 148.61 \\
25 & 18 & 6 & 3 & $377 \times 28$ & 155.94 \\
26 & 18 & 6 & 4 & $377 \times 28$ & 163.84 \\
27 & 18 & 6 & 5 & $377 \times 28$ & 173.68 \\
\hline & & & & & \\
\hline
\end{tabular}

Using GNA for both prestressing only and combined (prestressing + vertical) loading the values of maximal transverse membrane forces $n_{x}$, maximal combined equivalent membrane von Mises stresses $\sigma_{e}$, maximal vertical membrane deflection and maximal transverse arch deflection $u_{y}$ (in "membrane with arches") were determined. The comparison of results is shown in Table 2 in the form of respective ratios.

The ratios vary from 100 to $271 \%$. For example the distribution of the values for case No. 22 is shown in Figure 11 (transverse membrane forces $n_{x}$ ) and Figure 12 (equivalent membrane stresses $\sigma_{e}$ and vertical membrane deflections $u_{z}$ ), in which the ratios concerning prestressing (122\%) and deflections (164\%) are unacceptable.

From practical design point of view the ratios for arch spans up to $9 \mathrm{~m}$ seems to be acceptable, i.e. $\leq 112 \%$ for prestressing and $\leq 129 \%$ for membrane deflections (with the exception of shallow cases No. 4 and 8). Therefore, for such arrangements the interaction of arches with membrane may be neglected (i.e. analysis of the membranes with rigid supports and arches with resulting reactions gives reasonable results). Separated analysis for span above $10 \mathrm{~m}$ however, markedly underestimates both vertical membrane and horizontal arch deflections, which negatively influence cutting and prestressing process of membranes. Faulty results give separate analyses for majority of spans above $16 \mathrm{~m}$, where the necessary prestressing for "membrane with arches" in comparison with "membrane alone" should be much higher and in spite of such prestressing an enormous increase of membrane deflection must be expected.

The results may also be related to the arch slenderness (arch length to appropriate tube radius of gyration, see Table 1). For slenderness values $51 \div 100$ the ratios for prestressing ensuring the same total transverse force are in range of $100 \div 112 \%$ and ratios for the membrane vertical deflection between $101 \div 137 \%$. On the contrary, 


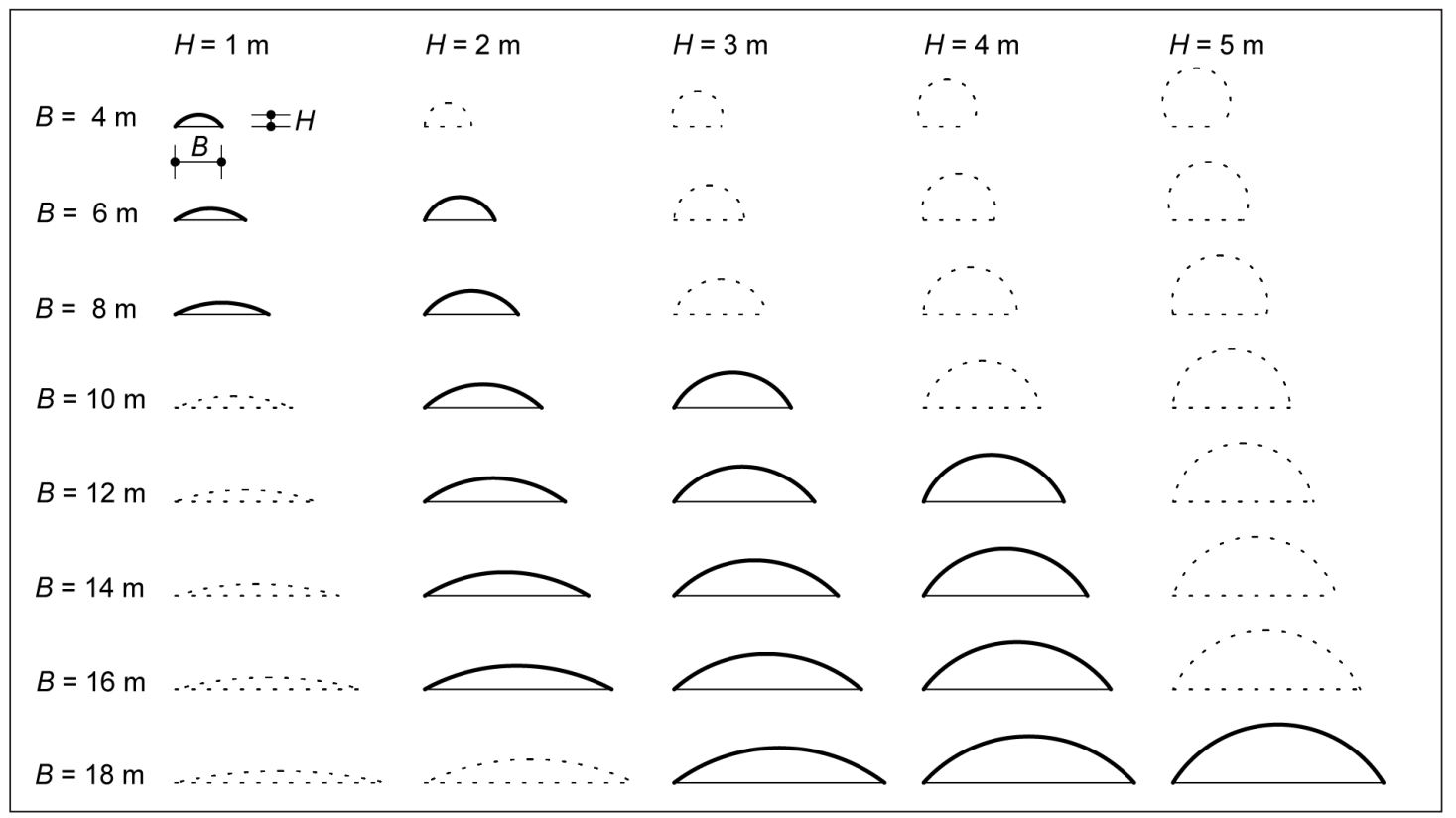

Fig. 9. Geometry of arches studied within the parametric study

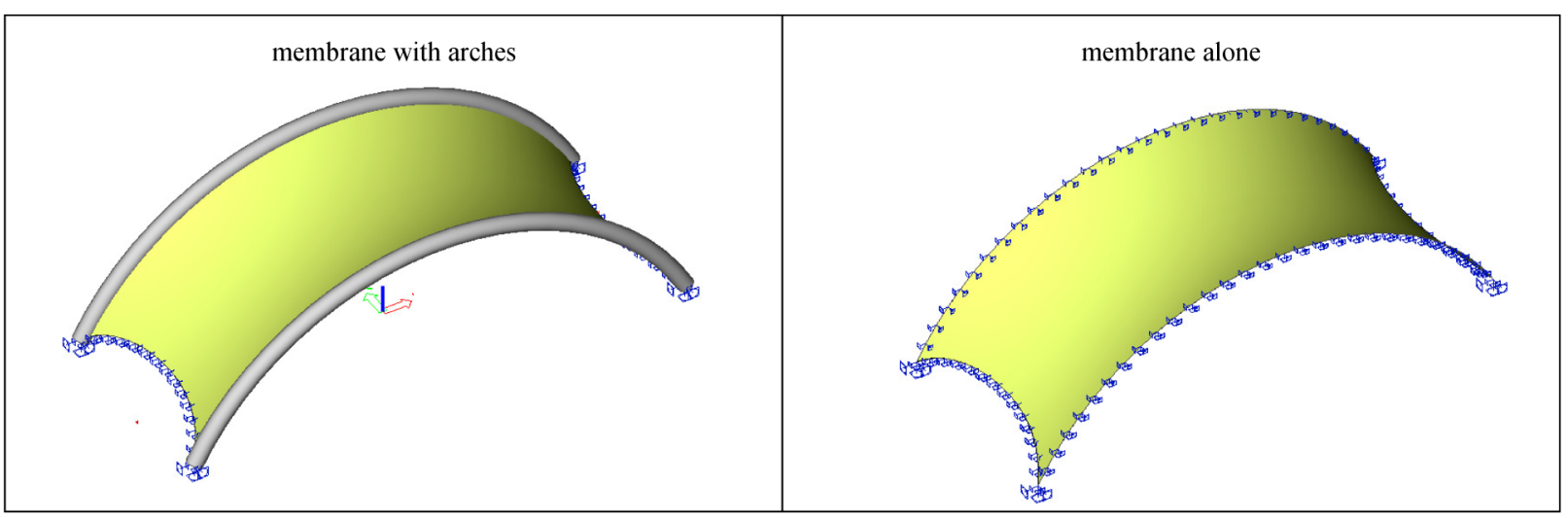

Fig. 10. Boundary conditions of arches studied within the parametric study

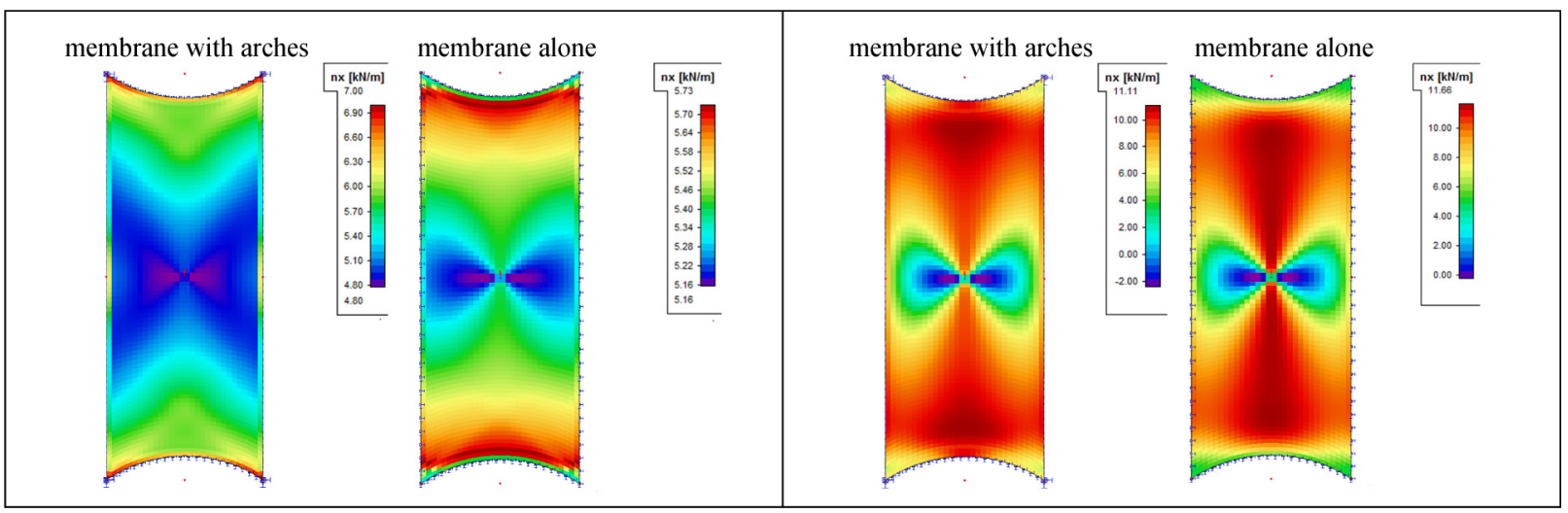

Fig. 11. Transverse membrane forces $n_{x}[\mathrm{~N} / \mathrm{mm}]$ in the membrane due to prestressing (left) and due to combined prestressing and vertical loading (right) 
Table 2. GNA results in the form of ratios "membrane with arches" to "membrane alone"

\begin{tabular}{|c|c|c|c|c|c|}
\hline \multirow[b]{2}{*}{ No. } & \multicolumn{5}{|c|}{ "membrane with arches" / "membrane alone" ratios in [\%] } \\
\hline & $\begin{array}{c}\text { Prestressing: } \\
\text { transverse forces } \\
n_{x, \max } / n_{x, \max }[\%]\end{array}$ & $\begin{array}{c}\text { Combined loading: } \\
\text { transverse forces } \\
n_{x, \max } / n_{x, \max }[\%]\end{array}$ & $\begin{array}{c}\text { Combined loading: } \\
\text { equivalent stresses } \\
\sigma_{e, \max } / \sigma_{e, \max }[\%]\end{array}$ & $\begin{array}{c}\text { Vertical membrane } \\
\text { deflections } \\
u_{z, \max } / u_{z, \max }[\%]\end{array}$ & $\begin{array}{c}\text { Transverse arch } \\
\text { deflection } \\
u_{y, \max }[\mathrm{mm}]\end{array}$ \\
\hline 1 & 103 & 102 & 97 & 106 & 0.4 \\
\hline 2 & 100 & 100 & 101 & 103 & 1.1 \\
\hline 3 & 100 & 101 & 90 & 101 & 2.2 \\
\hline 4 & 106 & 101 & 101 & 137 & 2.2 \\
\hline 5 & 112 & 108 & 110 & 112 & 3.6 \\
\hline 6 & 103 & 103 & 104 & 111 & 2.6 \\
\hline 7 & 101 & 101 & 95 & 105 & 3.6 \\
\hline 8 & 103 & 99 & 100 & 141 & 6.4 \\
\hline 9 & 100 & 90 & 92 & 129 & 8.7 \\
\hline 10 & 104 & 98 & 98 & 158 & 9.7 \\
\hline 11 & 109 & 99 & 101 & 179 & 12.9 \\
\hline 12 & 110 & 98 & 93 & 175 & 17.6 \\
\hline 13 & 99 & 96 & 97 & 144 & 10.8 \\
\hline 14 & 101 & 93 & 100 & 153 & 13.5 \\
\hline 15 & 100 & 100 & 89 & 145 & 18.8 \\
\hline 16 & 122 & 86 & 97 & 194 & 15.6 \\
\hline 17 & 114 & 92 & 100 & 196 & 17.8 \\
\hline 18 & 121 & 110 & 109 & 224 & 23.4 \\
\hline 19 & 111 & 97 & 97 & 147 & 17.7 \\
\hline 20 & 102 & 92 & 93 & 166 & 19.7 \\
\hline 21 & 111 & 94 & 102 & 201 & 26.0 \\
\hline 22 & 122 & 96 & 92 & 164 & 24.6 \\
\hline 23 & 112 & 95 & 100 & 180 & 26.6 \\
\hline 24 & 112 & 90 & 98 & 202 & 31.8 \\
\hline 25 & 126 & 94 & 100 & 199 & 36.3 \\
\hline 26 & 128 & 91 & 100 & 231 & 40.9 \\
\hline 27 & 134 & 100 & 104 & 271 & 48.8 \\
\hline
\end{tabular}

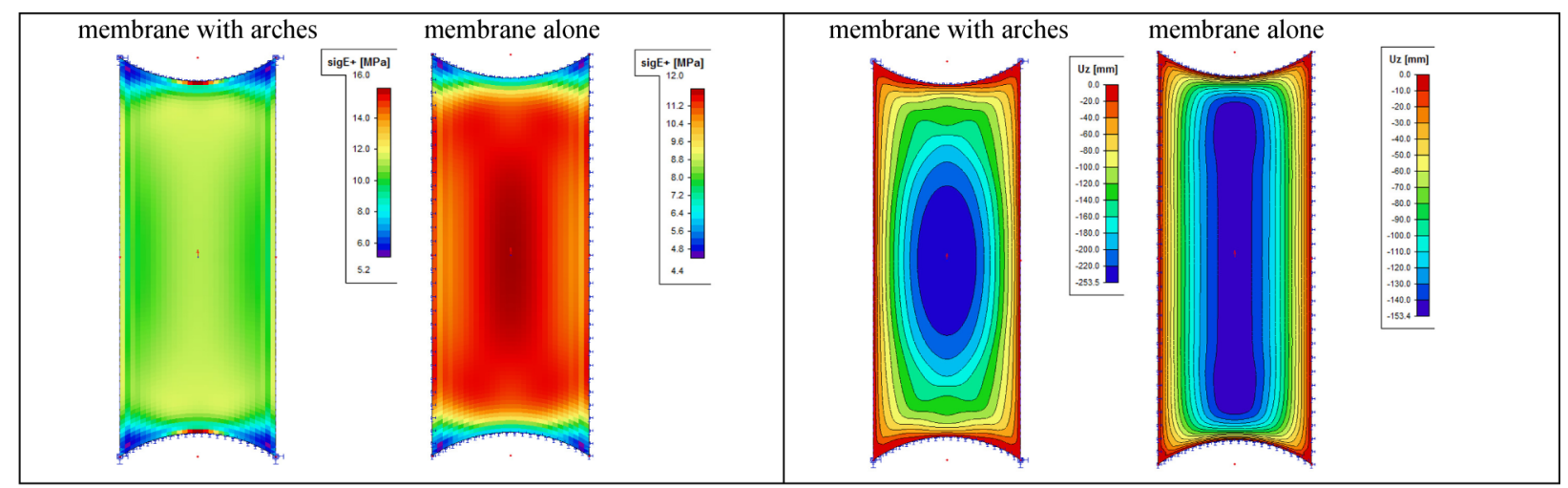

Fig. 12. Transverse combined equivalent membrane stresses $\sigma_{e}$ (left) and vertical membrane deflections $u_{z}$ (right) 
slenderness' $100 \div 174 \%$ give the same ratios in range of $99 \div 134 \%$ for prestressing and $129 \div 271 \%$ for deflections, which are unacceptable.

\section{Conclusions}

The correct analysis of textile membranes embedded into a steel structure requires geometrically and materially nonlinear analysis with imperfections (GMNIA), available with specialized software. Nevertheless, the use of simple common "structural frame" software for both the supporting steelwork and a separate geometrically nonlinear analysis of incorporated prestressed membrane is often the choice of designers in rather simple membrane structures.

Using simplified material linear isotropic properties the membranes between arches according to Figure 1 may be designed with common "structural frame" software neglecting joint behaviour (i.e. using design of the membrane alone as an isolated element), provided:

- Geometrically nonlinear analysis (GNA) for both membranes and steelwork is used.

- Prestressing must be used as the basic entry loading.

- The arch span or arch slenderness is limited (approx. to $9 \mathrm{~m}$ of the former or to 100 of the latter).

- Introduction of a suitable elastic support provided by the arches may improve the results but is rather a demanding task while a simple uniform distribution of an elastic support along the arches is not sufficient. Without dispute the above results, the joint modelling (especially using specialized software with proper membrane nonlinear behaviour) of the membrane with actual supporting steelwork is however always preferred. More complicated structures require nonlinear analysis with imperfections (GMNIA) using mentioned relevant input data concerning inherent membrane anisotropic and nonlinear material properties and covering also slacks of cables/rods due to their own weight. Furthermore, methods of assembly are also not covered in this paper, which can substantially affect the resulting geometry and state of stress of the membranes (including the influence of fabric pattern in the unstressed state), necessary rectification and membrane cutting.

\section{Funding}

This work was supported by the Czech Grant Agency, grant GACR No. 105/13/25781S.

\section{Disclosure statement}

Authors declare to have no competing financial, professional, or personal interests from other parties.

\section{References}

Bonet, J.; Mahaney, J. 2001. Form finding of membrane structures by the updated reference method with minimum mesh distortion, International Journal of Solids Structures 38(32-33): 5469-5480.

https://doi.org/10.1016/S0020-7683(00)00382-6
Capova, J. 2010. Form finding of membrane structures: PhD thesis. Faculty of Civil Engineering, Czech Technical University in Prague. 143 p.

Cottrell, J. A.; Hughes, T. J. R.; Bazilevs, Y. 2009. Isogeometric analysis toward integration of CAD and FEA. John Wiley \& Sons. 333 p. https://doi.org/10.1002/9780470749081

Dinh, T. D.; Rezaei, A.; De Laet, L.; Mollaert, M.; Van Hemelrijck, D.; Van Paepegem, W. 2014. A new elasto-plastic material model for coated fabric, Engineering Structures 71: 222-233. https://doi.org/10.1016/j.engstruct.2014.04.027

Easy Software. 2014. technet GmbH Berlin-Stuttgart [online], [cited 10 February 2014]. Available from Internet: http://www.technet-gmbh.com

EN 1993. Eurocode 3: Design of steel structures. European Standard. Comité Européen de Normalisation, Brussels.

Formfinder Software GmbH. 2006-2015. Wien [online], [cited 15 March 2015]. Available from Internet: http://www.formfinder.at/main/software/

Foster, B.; Mollaert, M. 2004. European design duide for tensile surface structures. TensiNet. $354 \mathrm{p}$.

Galliot, C.; Luchsinger, R. H. 2009a. A simple model describing the non-linear biaxial tensile behaviour of PVC/coated polyester fabrics for use in finite element analysis, Composite Structures 90(4): 438-447. https://doi.org/10.1016/j.compstruct.2009.04.016

Galliot, C.; Luchsinger, R. H. 2009b. Non-linear properties of PVC-coated fabrics used in tensairity structures, in International Conference on Composite Materials (ICCM17), 27-31 July 2009, Edinburgh, UK. 10 p.

Gosling, P. 2007. Basic philosophy and calling notice. Tensinet analysis \& material working group, Tensinews 13: 12-15.

Gründig, L.; Moncrieff, E.; Singer, P.; Ströbel, D. A. 2000. History of the principal developments and application of the force density method in Germany, in $4^{\text {th }}$ International Colloquium on Computation of Shell \& Spatial Structures (IASS-IACM), 5-7 June 2000, Chania-Crete, Greece. 13 p.

ixForten 4000. 2015 [online], [cited 15 March 2015]. Available from Internet: http://www.ixforten.com/

Kato, S.; Yoshino, T.; Minami, H. 1999. Formulation of constitutive equations for fabric membranes based on concept of fabric lattice model, Engineering Structures 21(8): 691-708. https://doi.org/10.1016/S0141-0296(98)00024-8

Lewis, W. J. 2003. Tension structures - form and behaviour. Thomas Telford Publishing. $206 \mathrm{p}$. https://doi.org/10.1680/tsfab.32361

Linkwitz, K. 1999. About formfinding of double-curved structures, Engineering Structures 21(8): 709-718. https://doi.org/10.1016/S0141-0296(98)00025-X

Maurin, B.; Motro, R. 1998. The surface stress density method as a form-finding tool for tensile membranes, Engineering Structures 20(8): 712-719. https://doi.org/10.1016/S0141-0296(97)00108-9

membrane NDN software. 2015 [online], [cited 30 March 2015]. Available from Internet: http://www.ndnsoftware.com/

Pargana, J. B.; Leitao, W. M. A. 2015. A simplified stress-strain model for coated plain-weave fabrics used in tensioned fabric structures, Engineering Structures 84: 439-450. https://doi.org/10.1016/j.engstruct.2014.12.002

Rhino Membrane. 2015 [online], [cited 30 March 2015]. Available from Internet: http://www.rhino3d.com

Schek, H. J. 1974. The force density method for form finding and computations of general networks, Computer Methods in Applied Mechanics and Engineering 3(1): 115-134. https://doi.org/10.1016/0045-7825(74)90045-0

Seidel, M. 2009. Tensile surface structures - a practical guide to cable and membrane construction. John Wiley \& Sons. 243 p. https://doi.org/10.1002/9783433600269 
Siev, A.; Eidelman, J. 1964. Stress analysis of prestressed suspended roofs, Journal of Structural Engineering ASCE 90(4): 103-122.

SOFiSTiK. 2014 [online], [cited 10 February 2014]. Available from Internet: http://www.sofistik.de/

Svoboda, O.; Machacek, J. 2014. Stabilization effect of a textile membrane on steel tube supporting arch, in $12^{\text {th }}$ International Conference on Steel, Space and Composite Structures (SS14), 28-30 May 2014, Prague, Czech Republic, 361-368.
Uhlemann, J.; Stranghöner, N.; Saxe, K. 2015. Stiffness parameters for architectural fabrics: an analysis of two determination procedures, Structural Engineering International 25(1): 9-19. https://doi.org/10.2749/101686614X14043795570291

Wakefield, D. S. 1999. Engineering analysis of tension structures: theory and practice, Engineering Structures 21(8): 680-690. https://doi.org/10.1016/S0141-0296(98)00023-6

Josef MACHACEK. Professor at Faculty of Civil Engineering of the Czech Technical University in Prague (Czech Republic). He published more than 300 research papers and teaching books on stability and elastic-plastic strength of thin steel plates, progressive thin-walled steel and stainless steel elements, composite steel and concrete structures and textile membranes cooperating with steel structures (see http://people.fsv.cvut.cz/ machacek/).

David JERMOLJEV. PhD, former PhD student under supervision of Professor Machacek. He graduated from Faculty of Civil Engineering of the Czech Technical University in Prague, works as a prominent designer of steel structures in EXCON Design Company in Prague. 